\title{
RNA-seq profiling of a radiation resistant and radiation sensitive prostate cancer cell line highlights opposing regulation of DNA repair and targets for radiosensitization
}

\author{
Arabella Young ${ }^{1,2,3 \dagger}$, Rachael Berry ${ }^{1 \dagger}$, Adele F Holloway ${ }^{4}$, Nicholas B Blackburn ${ }^{4}$, Joanne L Dickinson ${ }^{4}$, \\ Marketa Skala ${ }^{5}$, Jessica L Phillips ${ }^{4}$ and Kate H Brettingham-Moore ${ }^{1^{*}}$
}

\begin{abstract}
Background: Radiotherapy is a chosen treatment option for prostate cancer patients and while some tumours respond well, up to $50 \%$ of patients may experience tumour recurrence. Identification of functionally relevant predictive biomarkers for radioresponse in prostate cancer would enable radioresistant patients to be directed to more appropriate treatment options, avoiding the side-effects of radiotherapy.

Methods: Using an in vitro model to screen for novel biomarkers of radioresistance, transcriptome analysis of a radioresistant (PC-3) and radiosensitive (LNCaP) prostate cancer cell line was performed. Following pathway analysis candidate genes were validated using GRT-PCR. The DNA repair pathway in radioresistant PC-3 cells was then targeted for radiation sensitization using the PARP inhibitor, niacinimide.

Results: Opposing regulation of a DNA repair and replication pathway was observed between PC-3 and LNCaP cells from RNA-seq analysis. Candidate genes BRCA1, RAD51, FANCG, MCM7, CDC6 and ORC1 were identified as being significantly differentially regulated post-irradiation. qRT-PCR validation confirmed BRCA1, RAD51 and FANCG as being significantly differentially regulated at 24 hours post radiotherapy ( $p$-value $=0.003,0.045$ and 0.003 respectively). While the radiosensitive LNCaP cells down-regulated BRCA1, FANCG and RAD51, the radioresistant PC-3 cell line up-regulated these candidates to promote cell survival post-radiotherapy and a similar trend was observed for MCM7, CDC6 and ORC1. Inhibition of DNA repair using niacinamide sensitised the radioresistant cells to irradiation, reducing cell survival at 2 Gy from $66 \%$ to $44.3 \%$ ( $p$-value $=0.02$ ).

Conclusions: These findings suggest that the DNA repair candidates identified via RNA-seq hold potential as both targets for radiation sensitization and predictive biomarkers in prostate cancer.
\end{abstract}

Keywords: Radiation, Prostate cancer, RNA-seq, DNA repair, Sensitization

\section{Background}

Radiation therapy (RT) is commonly used in the treatment of prostate cancer. However, in many cases the survival of cancer cells following RT can result in recurrence and disease progression. Current data indicates that up to $50 \%$ of prostate cancer patients undergoing

\footnotetext{
* Correspondence: khmoore@utas.edu.au

${ }^{\dagger}$ Equal contributors

'School of Medicine, University of Tasmania, Private Bag 23, Hobart, TAS 7000, Australia

Full list of author information is available at the end of the article
}

RT experience recurrence of the disease within 5 years of treatment [1,2]. Regardless of tumour response to RT patients may endure the side-effects, including radiation proctitis, cystitis and erectile dysfunction (reviewed in [3]). A personalised approach to treatment is urgently needed allowing patients unlikely to benefit from conventional RT to be directed towards hypofractionated RT [4] or other therapeutic options.

Understanding the cellular factors contributing to resistance to RT is vital in order to design tests to screen patients prior to receiving therapy and to develop adjuvant

\section{Ciomed Central}

(c) 2014 Young et al.; licensee BioMed Central Ltd. This is an Open Access article distributed under the terms of the Creative Commons Attribution License (http://creativecommons.org/licenses/by/4.0), which permits unrestricted use, distribution, and reproduction in any medium, provided the original work is properly credited. The Creative Commons Public Domain Dedication waiver (http://creativecommons.org/publicdomain/zero/1.0/) applies to the data made available in this article, unless otherwise stated. 
treatments to increase tumour cell death. Clinically predictive biomarkers currently in use, for example EGFR testing for treatment with tyrosine kinase inhibitors, rely on the marker being functionally relevant, playing an integral role in therapeutic mechanism. While it has long been known that RT operates by damaging DNA, to date there are no clinically predictive markers available to indicate the likelihood of an effective treatment outcome. It is conceivable that tumours which behave in a similar way in response to RT share similar features which can be used as predictive biomarkers and this hypothesis is currently under study for a range of cancers [5,6]. Prostate cancer currently lacks predictive biomarkers for treatment response and disease progression which are utilised successfully within other malignancies [7,8]. Clinicopathologic factors and prostate-specific antigen (PSA) levels currently aid decision making when selecting treatment for the individual patient however there is conflicting evidence as to the predictive and prognostic value of these markers [9-12]. While a number of markers have been identified as prognostic or predictors of recurrence following RT in prostate cancer [13-15] the studies published to date have failed to reach clinical utility and do not consider response to treatment.

In the search for a predictor of response, RNA sequencing (RNA-seq) offers an unbiased screening approach for potential novel biomarkers which relate to RT response. This study compared the post-irradiation transcriptome of a radiation resistant (PC-3) versus radiosensitive prostate cancer cell line ( $\mathrm{LNCaP})$. Previous work has demonstrated that these two cell lines have opposing radiosensitivity [16-18] however to date the transcriptome of these cell lines post-irradiation has not been characterised. RNA-seq was used to gain a global perspective of transcriptional changes to investigate the factors integral in response to RT. From the variation in transcriptional activity, specific pathways which relate to differential response were revealed and validated by qRT-PCR. A candidate pathway was selected and targeted for inhibition to determine whether RT sensitisation was possible.

\section{Methods}

\section{Cell culture}

The human prostate cancer LNCaP cell line (ATCC, USA) was cultured in RPMI 1640, while PC-3 cells (ATCC, USA) were grown in Ham's F-12 K medium. Media was supplemented with $10 \%$ FBS and penicillin/streptomycin. For the sensitisation experiments $\mathrm{PC}-3$ cells were treated with $0.1 \mathrm{mM}$ niacinimide (Sigma-Aldrich) for 24 hours prior to and 8 days post-irradiation. This study does not use any human subjects or human material other than continuous cell lines.

\section{Irradiation set-up}

Radiotherapy treatment of prostate cancer cell lines was carried out at the Holman Clinic at the Royal Hobart Hospital, Tasmania, Australia. Irradiation was performed using the $\operatorname{Varian}^{\oplus}$ Clinac $^{\oplus}$ 23Ex Linear Accelerator (Varian Medical Systems, Australia) which delivered doses between 2 and 8 Gray (Gy) at 600 monitor units (MU)/min.

\section{Clonogenic cell survival assays}

Prostate cancer cell lines were seeded at $1 \times 10^{3}$ cells/well (PC-3) or $3 \times 10^{3}$ cells/well (LNCaP) and irradiated at 0,2 , 4 or 8 Gy. After 14 days of colony growth, medium was removed and cells washed once in $1 \mathrm{ml}$ of PBS. Colonies were fixed with $700 \mu \mathrm{L}$ of 3:1 methanol to glacial acetic acid for 5 minutes. Fixative agent was removed and wells air-dried completely prior to staining. Cells were stained for $30 \mathrm{mi}-$ nutes in $500 \mu \mathrm{L}$ of $1.0 \%$ methylene blue (Sigma-Aldrich, USA) in 50\% ethanol. Colonies were counted when proliferation from a single viable cell exceeded 50 cells within the colony. Percentage cell survival was determined as the number of colonies post-treatment relative to the number of colonies within the corresponding 0 Gy control.

\section{RNA isolation}

RNA was extracted using TRI reagent ${ }^{\bullet}$ (Sigma-Aldrich, USA). For samples undergoing RNA-seq analysis RNA was subjected to further purification including DNase treatment for 15 minutes at room temperature and a second purification step utilising the RNeasy Plus Micro Kit (Qiagen, USA).

\section{RNA-seq}

RNA integrity was confirmed using the Agilent 2100 Bioanalyser (Agilent Technologies, USA). Next-generation sequencing was performed at the Australian Genome Research Facility (AGRF) using the Illumina Hiseq-2000 RNA-seq sequence production system (50 cycle, single end). Sequences were assessed for quality and then aligned against the human genome using the Tophat aligner (http://tophat.cbcb.umd.edu/). Comparison between the 0 , 6 and 24 hour timepoints was performed using Cuffdiff (http://cufflinks.cbcb.umd.edu/).

\section{Ingenuity pathway analysis}

The Ingenuity Pathway Analysis (IPA) program (https:// analysis.ingenuity.com/) was utilised to perform a core analysis on the dataset gene files generated by RNA-seq. The gene ID, fold change $(>2)$ and q-value $(<0.05)$ were used for further analysis. Raw data was analyzed using the flexible format and genes identified through human gene symbols in association with the HUGO Gene Nomenclature Committee (HGNC) and Entrez Gene guidelines. Direct and indirect relationships between significant genes were considered. 


\section{Real-time PCR validation}

Following irradiation RNA was isolated at specific timepoints and reverse transcribed to cDNA using Superscript II reverse transcriptase (Invitrogen, USA). SYBR Green PCR amplification was performed on the Rotor-Gene 2000 real-time cycler (Corbett Research, Australia) using Quantitect SYBR Green PCR mastermix (Qiagen, Germany) according to the manufacturer's instructions in a total volume of $10 \mu \mathrm{l}$, containing $20 \mathrm{ng}$ of cDNA. Cycling conditions were as follows: $95^{\circ} \mathrm{C}$ for $15 \mathrm{~min} ; 95^{\circ} \mathrm{C}$ for $15 \mathrm{~s}, 60^{\circ} \mathrm{C}$ for $60 \mathrm{~s}$ for 35 cycles, followed by melt analysis from 60 to $95^{\circ} \mathrm{C}$. Primers are listed in Table 1 . Expression levels were normalised to the house-keeping gene GAPDH.

\section{Statistical analysis}

Statistical analysis and graph generation was performed in GraphPad Prism version 6.0d for Mac OSX, GraphPad Software, La Jolla California USA, www.graphpad.com. The clonogenic assay and gene expression assays were analyzed using repeated measures two-way ANOVA. Cell survival in response to niacinamide exposure was analyzed using repeated measures one-way ANOVA. Cell survival in response to niacinamide and radiation exposure was analyzed using repeated measures two-way ANOVA. The Sídák multiple comparison test was used following each analysis.

\section{Western blotting}

Nuclear extracts were prepared as previously described [19]. Protein concentrations were determined by Bradford Assay (Bio-Rad, USA). Protein extracts were run on a $12 \%$ Mini-PROTEAN ${ }^{\odot}$ TGX $^{\mathrm{TM}}$ pre-cast gel (Bio-Rad, USA) and transferred onto nitrocellulose membrane. Western-blot analysis was performed using anti-BRCA1, anti-RAD51

Table 1 Primer sets used in real time PCR

\begin{tabular}{ll}
\hline Primer & Sequence \\
\hline BRCA1 For & 5'-GACAGAGGACAATGGCTTCC-3' \\
BRCA1 Rev & 5'-AGCTCCTGGCACTGGTAGAG-3' \\
FANCG For & 5'-AAGGGGTCACATGAAGATGC-3' \\
FANCG Rev & 5'-GGACGGATCCAGCTCAAATA-3' \\
RAD51 For & 5'-TAGCTCAAGTGGATGGAGCA-3' \\
RAD51 Rev & 5'-TCTGGTTTCCCCTCTTCCTT-3' \\
MCM7 For & 5'-TTCGCGCCAATTCGGTTG-3' \\
MCM7 Rev & 5'-ACCTITCCTTCTCTAGCGCGT-3' \\
ORC1 For & 5'-CGATTGGCGCGAAGTTTCT-3' \\
ORC1 Rev & 5'-CTTGTGGGGTAGTGTGCCAT-3' \\
CDC6 For & 5'-CCGTAACCTGTTCTCCTCGT-3' \\
CDC6 Rev & 5'-TAGGTTGTCATCGCCCAGAC-3' \\
GAPDH For & 5'-AAATATGATGACATCAAGAAGGTGGT-3' \\
GAPDH Rev & 5'-AGCCCAGGATGCCCTTGAGGG-3' \\
\hline
\end{tabular}

and anti-Sp1 antibodies (Santa Cruz Biotechnology, USA) and the corresponding peroxidase-conjugated secondary antibodies (DAKO, Denmark). Proteins were visualized using the Supersignal West Pico Chemiluminescent kit (Pierce ThermoScientific, USA) according to the manufacturer's instructions.

\section{Results}

Clonogenic cell survival post-irradiation demonstrates a significant difference between LNCaP and PC-3 cells

LNCaP and PC-3 cells, isolated from prostate cancer lymph and bone metastases respectively, have previously been used as models for radiation sensitivity $[17,18]$. In order to confirm these cells behaved as per the literature in our irradiation set-up, the radiation sensitivity of these prostate cancer cell lines was confirmed via clonogenic assay following irradiation. In both cell lines decreased levels of survival were observed with increasing irradiation dose. The PC-3 cell line showed the greatest level of resistance to radiotherapy following 2 Gy irradiation with over $73 \%$ cell survival (Figure 1 ). In contrast, only $36 \%$ cell survival was measured for the LNCaP cell line indicating their increased sensitivity ( $p$-value 0.002$)$. In both cell lines less than $10 \%$ of cells were able to generate viable colonies following 4 Gy irradiation and less than $1 \%$ cell survival was observed after 8 Gy irradiation.

\section{Pathway analysis demonstrates DNA repair and replication were significantly upregulated in the radioresistant cells and downregulated in the radiosensitive cells}

To identify differences in genes and pathways affected by irradiation, RNA-seq was performed on the LNCaP and PC-3 cells. Following 2 Gy irradiation (equivalent to the fractionated irradiation dosage commonly received by patients) RNA was isolated at 0, 6 and 24 hours prior to sequencing via the Illumina Hiseq-2000 RNA-seq platform.

The gene lists generated for radiosensitive $\mathrm{LNCaP}$ and radioresistant PC-3 cells at 6 and 24 hours following 2 Gy irradiation showed large differences in both the number and type of genes that were transcriptionally activated. Irradiation appeared to impact transcriptional response to a greater extent within the PC-3 cell line with 399 genes significantly differentially regulated by 6 hours (using a 2 fold cut-off). In comparison, at the same time-point only 89 genes were significantly up- or down-regulated for the radiosensitive LNCaP cell line. An unbiased analysis of the gene lists obtained from RNA-seq was then used to uncover pathways involved in radioresponse. Interactions between significantly differentially regulated genes in each cell line were determined using Ingenuity Pathway Analysis (IPA). Two canonical pathways identified were shown to have opposing responses 24 hours after irradiation. The 


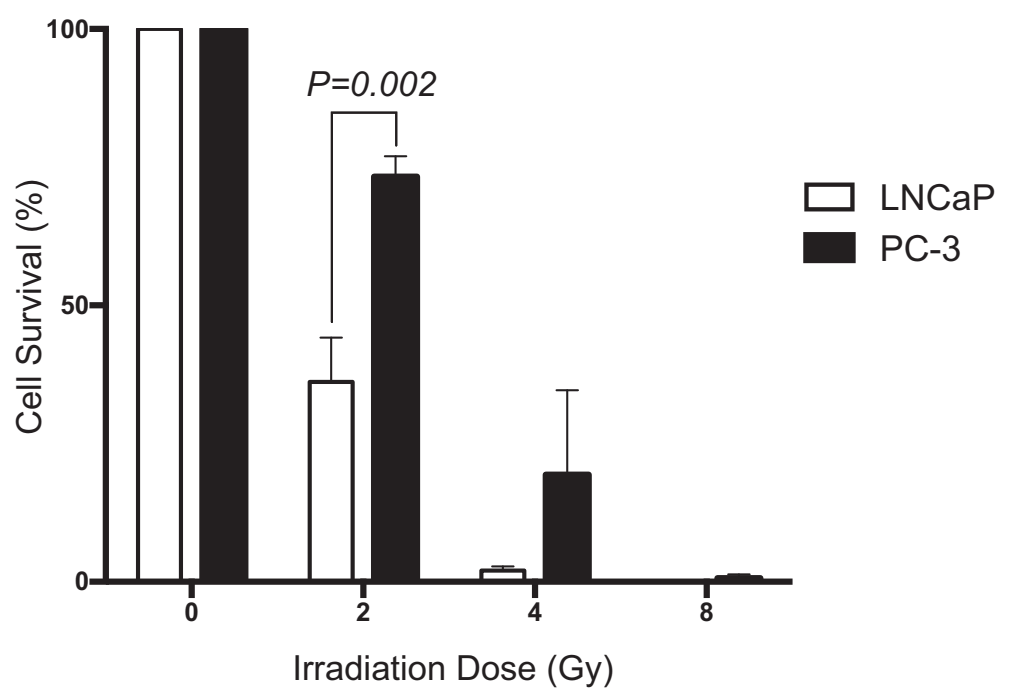

Figure 1 PC-3 and LNCaP cell survival following irradiation. Clonogenic assays were carried out to establish difference in cell survival between the two cell lines following radiotherapy treatment at 0, 2, 4 and $8 \mathrm{~Gy}$. Percentage cell survival at each irradiation dose was determined as the proportion of colonies present after treatment $(2,4$ and $8 \mathrm{~Gy})$ in comparison to colony numbers within the untreated control sample at 0 Gy. The mean and SEM from three biological replicates are shown, $p$-value determined by two way ANOVA and Sidak's post test.

top pathway affected 24 hours post-irradiation for both cell lines was a DNA repair pathway. While key genes within this pathway were significantly up-regulated in the radioresistant PC-3 cell line (Figure 2A) the same subset of genes were oppositely regulated, displaying downregulation within the radiosensitive $\mathrm{LNCaP}$ cell line (Figure 2B). These oppositely regulated genes include BRCA1, RAD51 and FANCG.

The cell cycle control of DNA replication pathway was also observed as the other top canonical pathway affected by irradiation in the cell lines (Additional file 1: Figure S1). Up-regulation of ORC1, CDC6 and the MCM genes was observed at 6 and 24 hours after irradiation in PC-3 cells. In contrast, the LNCaP cell line showed significant down-regulation of the equivalent subset of genes at 24 hours.

Another potential way to find a predictive biomarker is to screen for genes with strong basal expression. The top 10 genes identifiable by RNA-seq were filtered and are listed in Additional file 2: Table S1 along with the contrasting value in the alternate cell line. While these genes may prove to be relevant predictors, a predictive biomarker is more robust when it is functionally relevant. Therefore the focus of this study remained on the genes involved in the two key pathways responsible for differential radiation response.

BRCA1, RAD51 and FANCG mRNA display significant opposing regulation in response to radiotherapy in the radiosensitive versus radioresistant cells

In order to validate the candidate genes identified by RNAseq, expression levels following 2 Gy irradiation were assessed using qRT-PCR. The LNCaP cell line demonstrated a slight increase in BRCA1 expression at 6 hours post RT followed by down-regulation within 24 hours post RT to 0.2 fold of the basal level. In contrast BRCA1 mRNA was up-regulated in PC-3 cells post-irradiation to 1.5 fold by 24 hours. Comparison of BRCA1 expression in the LNCaP and PC-3 cell line at 24 hours confirmed opposing regulation with a significant difference observed (p-value 0.003).

FANCG mRNA also displayed significant opposing regulation at 24 hours post $\mathrm{RT}$ being down-regulated by 0.4 fold in the LNCaP cells and up-regulated by 1.5 fold in the PC-3 cells ( $p$-value 0.003, Figure 3B).

RAD51 mRNA levels decreased by 0.4 fold basal levels at 24 hours in the LNCaP cells (Figure 3C). In contrast, RAD51 expression was up-regulated in the PC-3 cells by 1.8 and 2.6 fold at 6 and 24 hours post RT respectively. This difference in RAD51 mRNA expression between the two cell lines at 24 hours was shown to be significant ( $p$-value 0.045$)$. The DNA replication candidates MCM7, ORC1 and CDC6 mRNA levels displayed a similar trend with down-regulation in the LNCaP cells and up-regulation in the PC-3 cells at 24 hours (Figure 3D-F). However, this difference was found to be non significant.

Nuclear levels of BRCA1 and RAD51 protein diminished in the radiosensitive cells while increasing in the radioresistant cells post-irradiation

BRCA1 and RAD51 protein expression was then examined as these genes showed significant differential responses following radiation treatment and are directly involved in DNA repair. Western blot analysis was performed on 


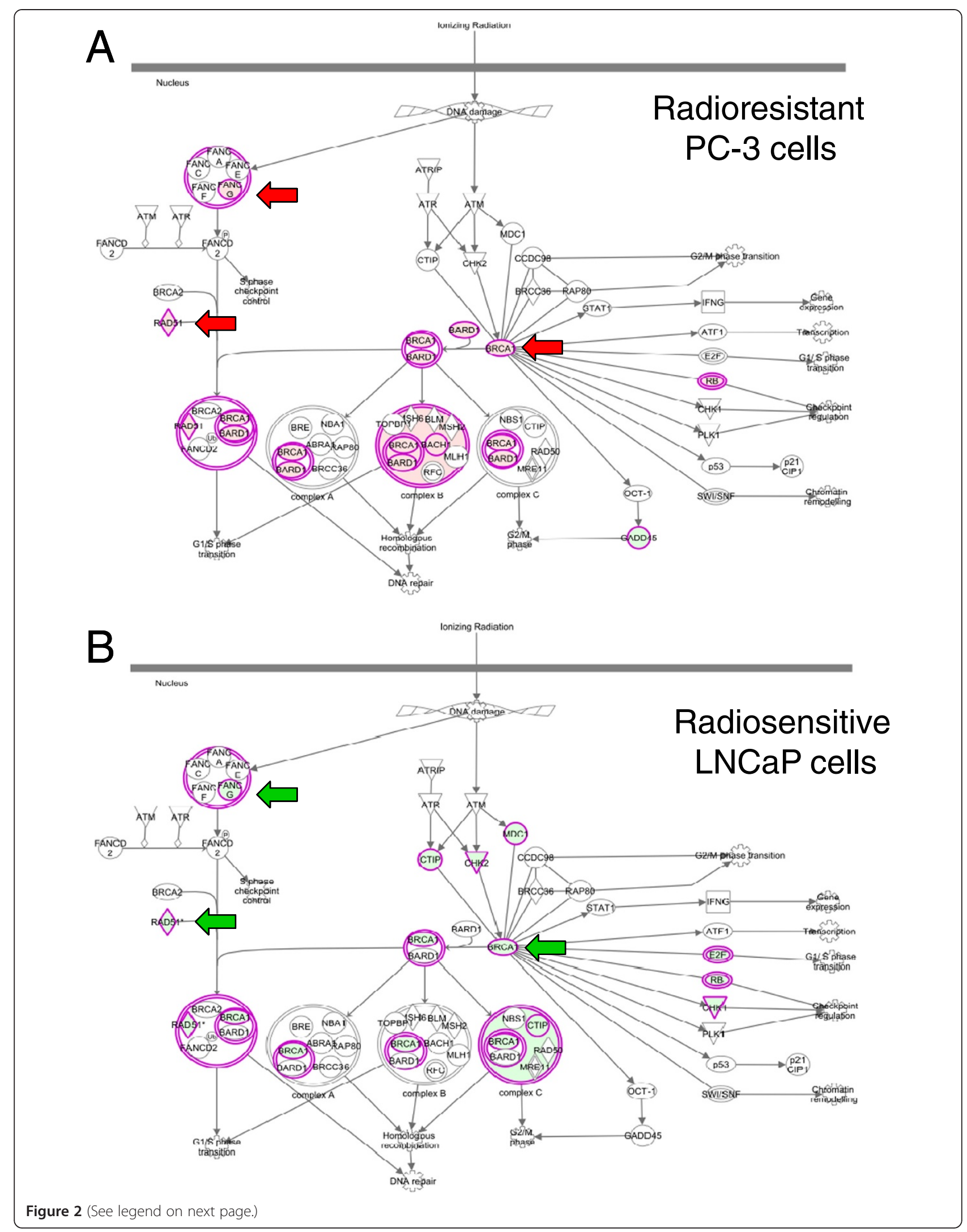


(See figure on previous page.)

Figure 2 Pathway analysis highlights opposing regulation of a DNA repair pathway in radioresistant versus radiosensitive cells. Gene lists determined by RNA-seq for the (A) PC-3 and (B) LNCaP cell lines 24 hours after 2 Gy irradiation were analysed using IPA. DNA repair pathways were identified as being significantly altered in response to RT ( $q$-value $1 \times 10^{-10}$ ). Significantly up-regulated genes are coloured red and down-regulated green, those present within our data set but not significant are shown in grey. Significant genes were defined as reporting a log fold $_{2}$ change $>1$ and a $q$-value $<0.05$. Arrows indicate gene products which were found to be oppositely regulated.

nuclear extracts from non-irradiated and irradiated (2 Gy) cells. Multiple BRCA1 isoforms were detected in the $\mathrm{LNCaP}$ cell line at approximately $220 \mathrm{kDa}$, along with the highly abundant 81 and $85 \mathrm{kDa}$ isoforms (Figure 4). While the levels of full length BRCA1 $(220 \mathrm{kDa})$ remained relatively stable across all time points, the smaller isoforms decreased from 0 to 24 hours post RT. In the PC-3 cell line this lower band was barely detectable at the 0 hour time-point but increased at 24 hours and a similar trend was observed for the full length BRCA1 protein. Another larger band was also detected at $250 \mathrm{kDa}$ being present in the irradiated and nonirradiated PC-3 cells. This band was relatively consistent across all treatment time-points for the PC-3 cells while it was also faintly detected in irradiated $\mathrm{LNCaP}$ cells potentially representing phosphorylated BRCA1.

Consistent with the differential transcriptional regulation in the two cell lines (Figure 3C) RAD51 expression decreased following RT in the LNCaP cells with a noticeable reduction in expression at 24 hours. In contrast up-regulation of RAD51 was observed at 6 hours post $\mathrm{RT}$ in the PC-3 cell line, and appeared to remain greater than the basal level at 24 hours post RT. The detection of a strong, second band just below $34 \mathrm{kDa}$ was observed in the PC-3 cells at all time points. This second band was confirmed to be a novel non-functional RAD51 splice variant (Additional file 3 and Additional file 4: Figure S2). The amplicon lacked the sequence corresponding to exon 9 of RAD51, a previously identified sequence variant [20] however the variant sequenced from the PC-3 cells was also missing $130 \mathrm{bp}$ of the 3 prime end of exon 8 . The predicted amino acid sequence of the variant consists of codons 1 to 214 and 299 to 339 of full length RAD51. The translated protein contains the Walker A ATP binding motif, but is lacking the Walker B ATP binding motif.

\section{The PARP inhibitor niacinamide successfully sensitised radioresistant prostate cancer cells to irradiation}

Poly ADP-ribose polymerase (PARP) inhibitors have previously been shown to inhibit DNA repair and down-regulate BRCA1 and RAD51 [21]. To determine whether radioresistant cells could be rendered sensitive by targeting the DNA repair pathway, the PARP inhibitor niacinamide was added to cells prior to irradiation. Prior to sensitisation assays the toxicity of niacinamide was determined and the optimal concentration selected as a low and clinically relevant dosage without a significant effect on cell survival (Figure 5A).

Cells were treated with $0.1 \mathrm{mM}$ niacinimide for 24 hours prior to irradiation and 8 days post-irradiation. Cells were irradiated at $0,2,4$ and 8 Gy and survival assessed via clonogenic assay. As shown in Figure 5B, for untreated PC-3 cells approximately 66\% cell survival was measured following 2 Gy irradiation. Treatment of cells with niacinamide significantly reduced cell survival to $44.3 \%$ ( $p$-value 0.02 ). This result was reiterated at 4 Gy with $18 \%$ of untreated cells surviving in contrast to cells sensitised with niacinamide exhibiting only 9\% cell survival (Figure 5B). Following 8 Gy irradiation in untreated cells, 7\% cell survival was observed while in contrast no formation of viable colonies within the niacinamide-treated PC-3 cells was apparent.

\section{Discussion}

The genetic heterogeneity observed in prostate cancer results in tumours from different individuals displaying significant variation in response to treatment [22,23]. Understanding the molecular pathology that contributes to this variation will enable tailoring treatment to specific tumour subtypes [24,25]. In order to gain insight into the molecular mechanism underpinning radiation sensitivity an unbiased approach was employed to identify differential gene expression relating to radioresponse. It has long been known that ionising radiation induces several forms of DNA damage [26,27] therefore, it was not surprising that the two most significant pathways observed to be altered following irradiation relate functionally to DNA repair and replication. In a previously unreported finding, these pathways were shown to be oppositely regulated in the radioresistant PC-3 cell line versus the radiosensitive $\mathrm{LNCaP}$ cell line. The radioresistant cells, by actively up-regulating genes in these pathways promoted cell survival. In contrast the radiosensitive cells inhibit expression of these very same genes, leading to cell death. The time taken to initiate DNA repair following irradiation has been previously identified as a major factor in determining radioresponse [28-30]. Identifying the level of response of these genes during the initial acute phase following irradiation may indicate the level of radiosensitivity.

The regulation of DNA repair and replication genes BRCA1, RAD51, FANCG, ORC1, CDC6 and MCM7 correlated with radiation sensitivity in the $\mathrm{LNCaP}$ and $\mathrm{PC}-3$ 
A

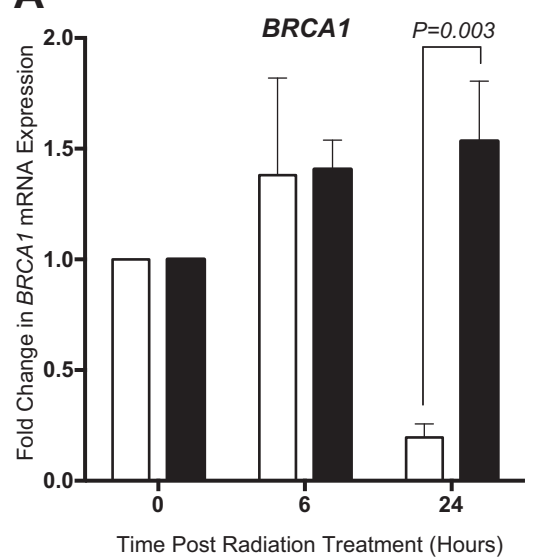

C

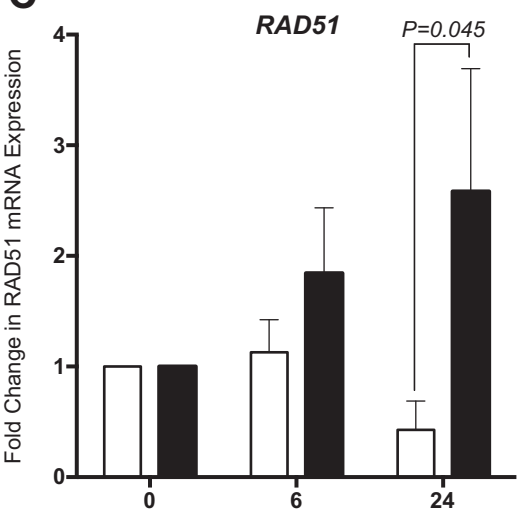

Time Post Radiation Treatment (Hours)

E

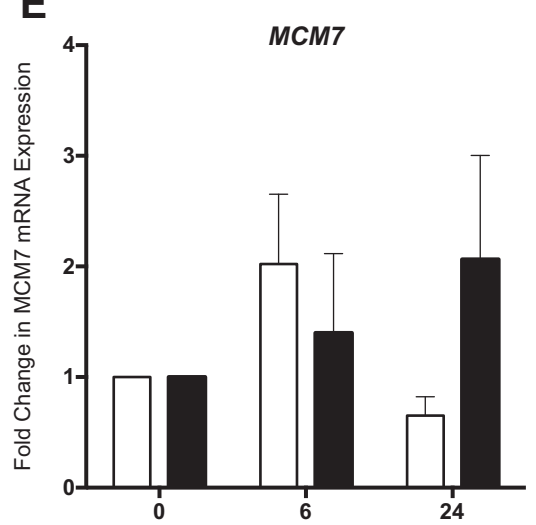

Time Post Radiation Treatment (Hours)
B

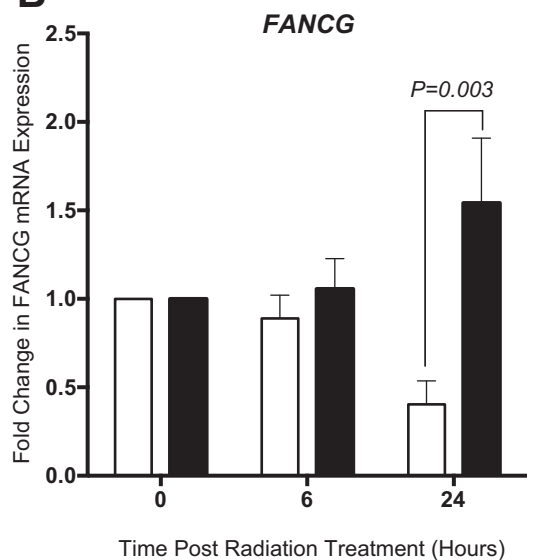

D

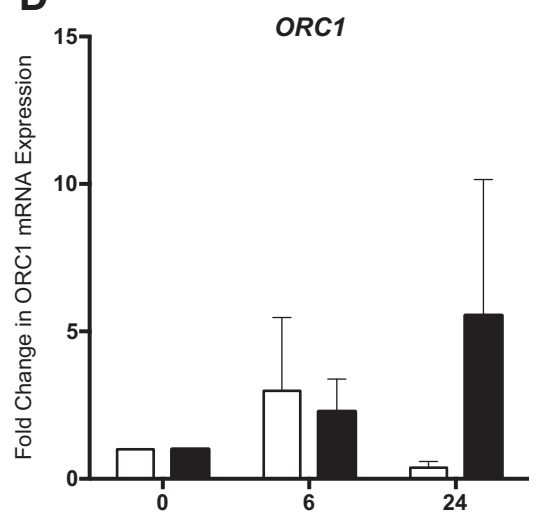

Time Post Radiation Treatment (Hours)

$\mathbf{F}$

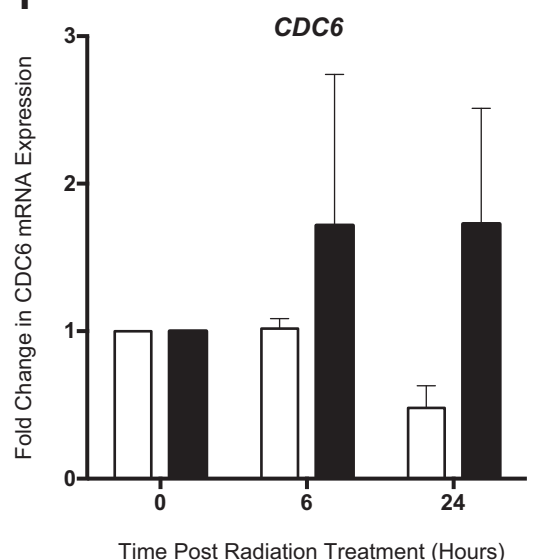

PC-3

Figure 3 Regulation of candidate gene expression in response to radiotherapy in LNCaP and PC-3 cell lines. Cells were exposed to 2 Gy irradiation and RNA was extracted at 0 (non-irradiated) 6 and 24 hours post RT. CDNA was amplified via real-time PCR using primers designed against (A) BRCA1, (B) FANCG, (C) RAD51, (D) ORC1, (E) MCM7, (F) CDC6 and expression levels normalised qRT-PCR to GAPDH. Fold change was calculated relative to the non-irradiated control. Error bars represent standard error of the mean from 3 biological replicates, $p$-values determined by two way ANOVA and Sidak's post test. 


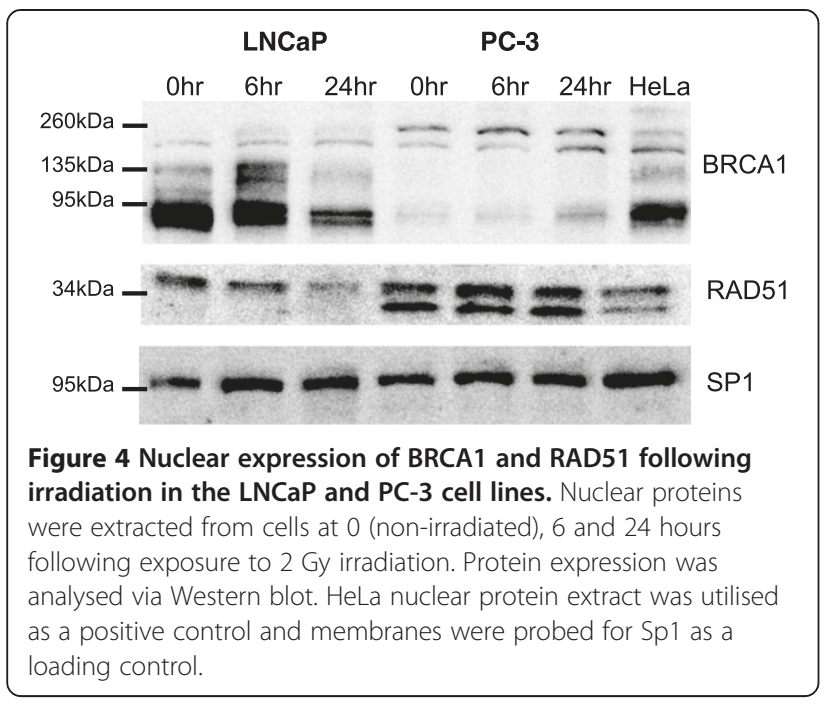

cell lines. While BRCA1, FANCG and RAD51 have previously been linked to various treatment responses in a number of cancers [31-33] limited research exists investigating the association between RT-induced regulation of these genes in radiation resistant prostate cancer. These genes appear to be key in regulating radiation response and therefore these pathways or their upstream regulators may prove to be a good predictor of treatment outcome. The DNA replication genes identified via RNA-seq warrant further investigation, while a trend was confirmed by qRT-PCR this was not significant. Future work in further characterising several of the candidates in patient biopsies is needed. With further investigation variants or basal patterns may prove to be predictive of response.

BRCA1 expression was found to have a strong association with radiation response, with significant opposing regulation observed between the two cell lines. BRCA1 has been identified as a primary regulator of the repair of DNA doublestranded breaks (DSB), which are formed on exposure to ionising radiation (reviewed in [34]). BRCA1 mutation and exogenous down-regulation has also previously been found to increase sensitivity to RT in a variety of cancer cell lines $[35,36]$ however no evidence is available for prostate cancer cells. The novel finding that prostate cancer cells with disparate radiosensitivity exhibit opposing regulation of BRCA1 following RT supports its involvement in determining radiation response. Interestingly, the initial RNA-seq analysis demonstrated that a key transcription factor in BRCA1 regulation, $E 2 F 1[37,38]$ was significantly down-regulated in the LNCaP cell line at 24 hours post-RT, which may explain the decrease in BRCA1 expression at the same time point. This transcription factor is also involved in regulating RAD51 and CDC6 expression $[39,40]$. In terms of potential implications for this finding it is unlikely that basal BRCA1 mRNA levels could be used as a predictive biomarker. While post RT levels of BRCA1 are more informative, it is unlikely patient biopsies could be taken at this point. Regardless, BRCA1 is an appealing target for sensitisation and screening BRCA1 mutations may help direct patients to their most optimal treatment.

It should also be noted that, as is the case in patient tumours, the LNCaP and PC-3 cell lines have many inherent differences. For example LNCaP cells are androgen sensitive and p53 positive $[41,42]$ while the PC-3 cells are androgen resistant and p53 null $[42,43]$. Regardless, p53 was not identified as being significantly differentially regulated in the p53 positive cell line post RT. Previous research has investigated p53 status as a predictive biomarker for radiation response in prostate cancer however, the large range of possible p53 mutations has led to conflicting results. Whilst some studies found that resistant tumours had a higher level of expression $[44,45]$ others concluded that p53 expression was comparable in both radiation sensitive and radiation resistant tumours $[46,47]$. Therefore, investigations into p53 targets, such as BRCA1 and RAD51, as predictors may be a more promising avenue for future research.

Radiation sensitisation strategies have been successful in the treatment of a variety of cancers [48-51] however clinically effective strategies have remained elusive in prostate cancer. This study demonstrated the efficacy of PARP inhibition in sensitising the radiation resistant $\mathrm{PC}-3$ prostate cancer cell line to the effects of RT. Niacinamide is a known inhibitor of PARPs which are involved in the repair of single-stranded breaks (SSB) [52]. All PARP inhibitors are based on the structure of niacinamide and use the same competitive binding strategy [53]. Importantly, PARP inhibition has also previously been demonstrated to down-regulate BRCA1 and RAD51 [21]. Much of the current research surrounds the use of PARP inhibitors as effective mono-therapy for breast and ovarian cancers with BRCA1 and BRCA2 mutations [54-56]. However, evidence for their radiation sensitisation capabilities is emerging from in vivo studies [57]. The use of niacinamide as a sensitisation strategy is an appealing possibility, due to the fact this compound has FDA approval and has beneficial effects (reviewed in [58]).

RAD51 is another promising target to enhance response to RT as clinically approved inhibitors are already available. RAD51 has previously been proposed as a possible target for radiosensitisation through inhibition using imatinib in prostate cancer xenografts [59]. Recent evidence demonstrates that imatinib down-regulates RAD51 expression and sensitises bladder and glioma cancer cells to RT $[60,61]$. Further molecular characterisation of the precise involvement of BRCA1 and RAD51 may contribute to more targeted radiosensitisation strategies.

\section{Conclusions}

This study is the first to characterise the post irradiation transcriptome of two prostate cancer cell lines with 


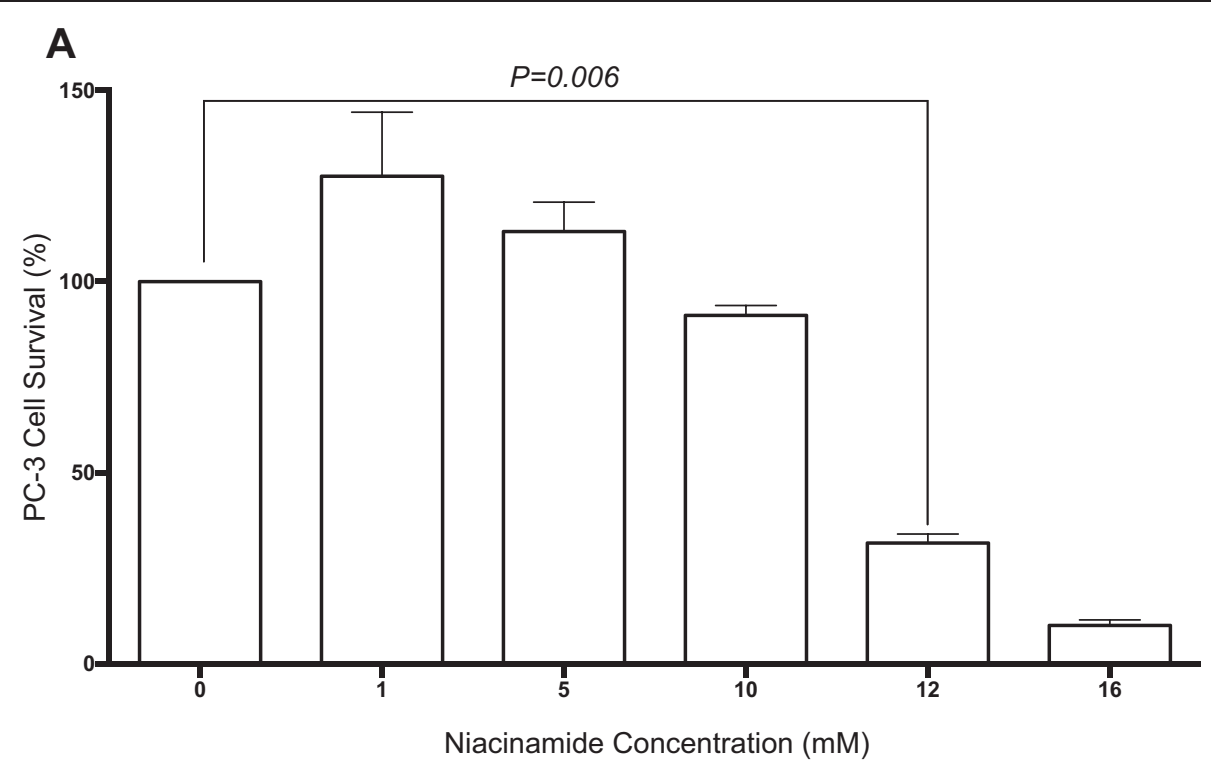

B

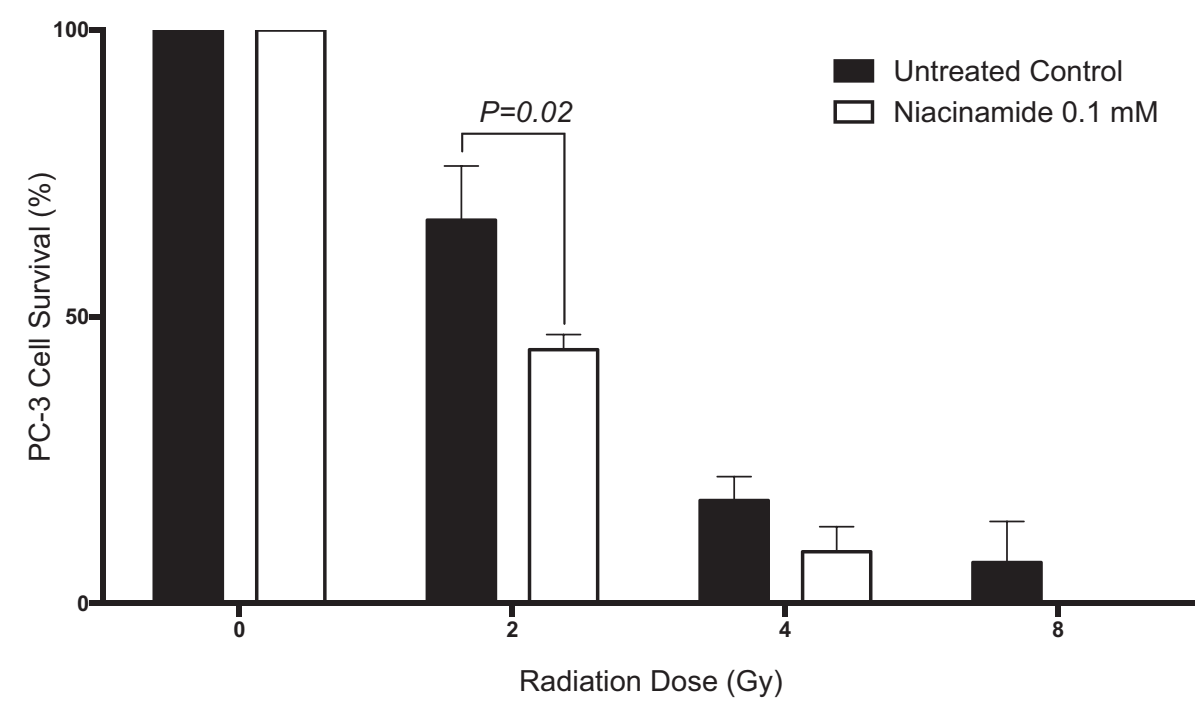

Figure 5 Adjuvant treatment with niacinamide significantly increases the radiation response of PC-3 cells. A) PC3 cells were incubated with varying concentrations of the PARP inhibitor niacinamide for 8 days and cell colonies of greater than 50 cells were counted. Cell survival percentages were calculated relative to the number of colonies counted in the untreated population. Error bars represent standard error of the mean from 3 biological replicates. p-values determined by one way ANOVA. B) PC-3 cells were incubated with or without niacinamide for 24 hours prior to and 8 days following exposure to $0,2,4$ or 8 Gy irradiation. Following incubation, colonies of greater than 50 cells were counted, and cell survival percentages were calculated relative to the appropriate non-irradiated colony counts. Error bars represent standard error of the mean from 3 biological replicates. $p$-values as determined by two way ANOVA and Sidak's post test.

divergent responses to RT commonly used in research. RNA-seq analysis revealed the potential for BRCA1 and RAD51 as biomarkers for radiation response. RT-induced regulation of both transcription and nuclear protein localisation was found to be associated with the differential radiation response of LNCaP and PC-3 prostate cancer cell lines. Given the role of BRCA1 and RAD51 in the homologous repair of DSBs, it is likely that their increased expression contributes to the repair of the DNA damage caused by RT to promote survival in resistant cells. In addition,
PARP has been identified as a putative target for adjuvant sensitisation strategies.

Translational research has an overall aim to be used clinically, providing benefits for patients, therefore the ability to validate in vitro based markers in vivo will be essential. Analysis of the behaviour of prostate cancer cell lines provides a reference point for possible traits that cause RT resistance. Importantly, the data generated by RNA-seq has provided potential leads on influential pathways, which are affected by irradiation. In addition, inhibition of gene 
products from these pathways can be used to sensitise prostate cancer cells to cell death following RT. Additional validation of these targets using patient biopsies will be imperative to understanding their potential clinical utility. Similarly, sensitisation agents require validation in mouse models (such as TRAMP and PTEN-induced prostatespecific cancer formation PTENfl/fl; probasin-Cre mice) prior to determining their suitability for clinical trials. Proving candidate markers and sensitisation agents to be clinically significant remains a definite challenge. However, with improving technology to recognise molecular subtleties which separate particular treatment responses, new opportunities for tailoring therapeutics will become available. This will enable increased translational research into the individualised management of prostate cancer patients providing advantages to the overall survival benefit received by patients. As niacinamide is a safe, well tolerated FDA approved vitamin supplement, its sensitisation effects could also be investigated by surveying patients taking such supplements followed by correlation with response data. Finally, the biomarkers and sensitisation strategy identified in this study may not only prove to be effective in prostate tumours, but may be relevant to numerous cancer types as a mechanism for inherent radiation resistance.

\section{Additional files}

Additional file 1: Figure S1. Differential regulation of cell cycle control of chromosomal replication pathway in PC-3 and LNCaP cells. IPA was performed on gene lists generated by RNA-seq of the A) PC-3 and B) LNCaP cell lines 24 hours following 2 Gy irradiation. The DNA replication pathway was identified as being significantly altered in response to RT $\left(q\right.$-value $\left.5 \times 10^{-8}\right)$. Significantly up-regulated genes are coloured red and down-regulated green, genes that showed differential expression at non-significant levels are shown in grey. Significant genes were defined as reporting a $\log _{2}$ fold change $>1$ and a $q$-value $<0.05$.

Additional file 2: Table S1. Top 10 known genes with highest basal expression in the LNCaP versus PC-3 cells.

Additional file 3: Additional methods.

Additional file 4: Figure S2. Alignment of the amino acid sequences of RAD51 and a novel RAD51 variant. PCR was performed utilising primers designed to amplify full length RAD51 and a previously identified variant, RAD51 $\triangle$ ex9. The smaller PCR product was extracted from the gel and sequenced. The resultant sequence was translated into the predicted amino acid sequence of the amplicon and aligned with the amino acid sequence of full length RAD51. Grey shading represents amino acids that are missing from the novel variant. Arrows indicate exons 8, 9 and 10. The Walker A ATP binding motif is indicated by the black box, whilst the Walker B ATP binding motif is indicated in bold type and underlined. *represents a stop codon.

\section{Abbreviations}

DSB: Double stranded break; Gy: Gray; IPA: Ingenuity pathway analysis; PARP: Poly ADP ribose polymerase; qRT-PCR: Quantitative reverse transcription polymerase chain reaction; RNA-seq: RNA sequencing; RT: Radiation therapy; SSB: Single stranded break.

\section{Competing interests}

The authors declare that they have no competing interests.

\section{Authors' contributions}

AY carried out experiments and analysis for Figures 1 and 2 and Additional file 1: Figure $S 1$ and contributed to the manuscript. RB carried out experiments for Figures 3, 4 and 5 and Additional file 4: Figure S2. JP carried out qRT-PCR for response to reviewers. NB performed statistical analysis. AH, MS and JD participated in the interpretation of data and drafting manuscript. KBM conceived study, participated in its design and co-ordination and drafting the manuscript. All authors have read and approved the final version of the manuscript.

\section{Acknowledgements}

This work was funded by a Cancer Council Tasmania grant. A. Young was supported by the Jim Bacon Foundation and Cancer Council Tasmania Honours Scholarship. R. Berry was supported by Cancer Council Tasmania Honours Scholarship. The authors would also like to thank the staff of the Holman Clinic at the Royal Hobart Hospital for their valuable contribution to the study.

\section{Author details}

${ }^{1}$ School of Medicine, University of Tasmania, Private Bag 23, Hobart, TAS 7000, Australia. ${ }^{2}$ Present address: QIMR Berghofer Medical Research Institute, Herston, Queensland 4006, Australia. ${ }^{3}$ School of Medicine, The University of Queensland, Herston, Queensland 4006, Australia. ${ }^{4}$ Menzies Research Institute Tasmania, University of Tasmania, Hobart, Tasmania 7000, Australia. ${ }^{5}$ Royal Hobart Hospital, Hobart, Tasmania 7000, Australia.

Received: 2 June 2014 Accepted: 21 October 2014

Published: 4 November 2014

\section{References}

1. Kuban DA, Thames HD, Levy LB, Horwitz EM, Kupelian PA, Martinez AA, Michalski JM, Pisansky TM, Sandler HM, Shipley WU, Zelefsky MJ, Zietman AL: Long-term multi-institutional analysis of stage T1-T2 prostate cancer treated with radiotherapy in the PSA era. Int J Radiat Oncol Biol Phys 2003, 57:915-928.

2. Khuntia D, Reddy CA, Mahadevan A, Klein EA, Kupelian PA: Recurrence-free survival rates after external-beam radiotherapy for patients with clinical T1-T3 prostate carcinoma in the prostate-specific antigen era: what should we expect? Cancer 2004, 100:1283-1292.

3. Budaus L, Bolla M, Bossi A, Cozzarini C, Crook J, Widmark A, Wiegel T: Functional outcomes and complications following radiation therapy for prostate cancer: a critical analysis of the literature. Eur Urol 2012, 61:112-127.

4. Anwar M, Weinberg V, Chang AJ, Hsu IC, Roach M 3rd, Gottschalk A: Hypofractionated SBRT versus conventionally fractionated EBRT for prostate cancer: comparison of PSA slope and nadir. Radiat Oncol 2014, 9:42.

5. Van Cutsem E, Kohne CH, Lang I, Folprecht G, Nowacki MP, Cascinu S, Shchepotin I, Maurel J, Cunningham D, Tejpar S, Schlichting M, Zubel A, Celik I, Rougier P, Ciardiello F: Cetuximab plus irinotecan, fluorouracil, and leucovorin as first-line treatment for metastatic colorectal cancer: updated analysis of overall survival according to tumor KRAS and BRAF mutation status. J Clin Oncol 2011, 29:2011-2019.

6. Chapman PB, Hauschild A, Robert C, Haanen JB, Ascierto P, Larkin J, Dummer R, Garbe C, Testori A, Maio M, Hogg D, Lorigan P, Lebbe C, Jouary T, Schadendorf D, Ribas A, O'Day SJ, Sosman JA, Kirkwood JM, Eggermont AM, Dreno B, Nolop K, Li J, Nelson B, Hou J, Lee RJ, Flaherty KT, McArthur GA: Improved survival with vemurafenib in melanoma with BRAF V600E mutation. N Engl J Med 2011, 364:2507-2516.

7. Cobleigh MA, Vogel CL, Tripathy D, Robert NJ, Scholl S, Fehrenbacher L, Wolter JM, Paton V, Shak S, Lieberman G, Slamon DJ: Multinational study of the efficacy and safety of humanized anti-HER2 monoclonal antibody in women who have HER2-overexpressing metastatic breast cancer that has progressed after chemotherapy for metastatic disease. J Clin Oncol 1999, 17:2639-2648.

8. Moyer VA: Screening for prostate cancer: U.S. Preventive Services Task Force recommendation statement. Ann Intern Med 2012, 157:120-134.

9. Corn BW, Hanks GE, Lee WR, Bonin SR, Hudes G, Schultheiss T: Prostate specific antigen density is not an independent predictor of response for prostate cancer treated by conformal radiotherapy. J Urol 1995, 153:1855-1859. 
10. Lin K, Lipsitz R, Miller T, Janakiraman S, Force USPST: Benefits and harms of prostate-specific antigen screening for prostate cancer: an evidence update for the U.S. Preventive Services Task Force. Ann Intern Med 2008 , 149:192-199.

11. Andriole GL, Crawford ED, Grubb RL 3rd, Buys SS, Chia D, Church TR, Fouad MN, Gelmann EP, Kvale PA, Reding DJ, Yokochi LA, O'Brien B, Clapp JD, Rathmell JM, Riley TL, Hayes RB, Kramer BS, Izmirlian G, Miller AB, Pinsky PF, Prorok PC, Gohagan JK, Berg CD, Plco Project Team, Hsing AW, Lacey JV Jr, Purdue M, Simpson NK, Cumberlin R, et al: Mortality results from a randomized prostate-cancer screening trial. N Engl J Med 2009, 360:1310-1319.

12. Quinn DI, Henshall SM, Haynes AM, Brenner PC, Kooner R, Golovsky D, Mathews J, O'Neill GF, Turner JJ, Delprado W, Finlayson JF, Sutherland RL, Grygiel JJ, Stricker PD: Prognostic significance of pathologic features in localized prostate cancer treated with radical prostatectomy: implications for staging systems and predictive models. J Clin Oncol 2001, 19:3692-3705

13. Roach M 3rd, Waldman F, Pollack A: Predictive models in external beam radiotherapy for clinically localized prostate cancer. Cancer 2009, 115:3112-3120.

14. Ishkanian AS, Zafarana G, Thoms J, Bristow RG: Array CGH as a potential predictor of radiocurability in intermediate risk prostate cancer. Acta Oncol (Stockholm, Sweden) 2010, 49:888-894.

15. Fernandez-Serra A, Rubio L, Calatrava A, Rubio-Briones J, Salgado R, Gil-Benso R, Espinet B, Garcia-Casado Z, Lopez-Guerrero JA: Molecular characterization and clinical impact of TMPRSS2-ERG rearrangement on prostate cancer: comparison between FISH and RT-PCR. BioMed Res Int 2013, 2013:465179.

16. Rudner J, Ruiner C-E, Handrick R, Eibl H-J, Belka C, Jendrossek V: The Akt-inhibitor Erufosine induces apoptotic cell death in prostate cancer cells and increases the short term effects of ionizing radiation. Radiat Oncol (London, England) 2010, 5:108.

17. Josson S, Xu Y, Fang F, Dhar SK, St Clair DK, St Clair WH: RelB regulates manganese superoxide dismutase gene and resistance to ionizing radiation of prostate cancer cells. Oncogene 2006, 25:1554-1559.

18. Amundson SA, Do KT, Vinikoor LC, Lee RA, Koch-Paiz CA, Ahn J, Reimers M, Chen Y, Scudiero DA, Weinstein JN, Trent JM, Bittner ML, Meltzer PS, Fornace AJ Jr: Integrating global gene expression and radiation survival parameters across the 60 cell lines of the National Cancer Institute Anticancer Drug Screen. Cancer Res 2008, 68:415-424.

19. Brettingham-Moore KH, Rao S, Juelich T, Shannon MF, Holloway AF: GMCSF promoter chromatin remodelling and gene transcription display distinct signal and transcription factor requirements. Nucleic Acids Res 2005, 33:225-234.

20. Park JY, Yoo HW, Kim BR, Park R, Choi SY, Kim Y: Identification of a novel human Rad51 variant that promotes DNA strand exchange. Nucleic Acids Res 2008, 36:3226-3234.

21. Hegan DC, Lu Y, Stachelek GC, Crosby ME, Bindra RS, Glazer PM: Inhibition of poly(ADP-ribose) polymerase down-regulates BRCA1 and RAD51 in a pathway mediated by E2F4 and p130. Proc Natl Acad Sci U S A 2010, 107:2201-2206.

22. Anandadas CN, Clarke NW, Davidson SE, O'Reilly PH, Logue JP, Gilmore L, Swindell R, Brough RJ, Wemyss-Holden GD, Lau MW, Javle PM, Ramani VA Wylie JP, Collins GN, Brown S, Cowan RA: Early prostate cancer-which treatment do men prefer and why? BJU Int 2011, 107:1762-1768.

23. Zelefsky MJ, Kattan MW, Fearn P, Fearon BL, Stasi JP, Shippy AM, Scardino PT: Pretreatment nomogram predicting ten-year biochemical outcome of three-dimensional conformal radiotherapy and intensity-modulated radiotherapy for prostate cancer. Urology 2007, 70:283-287.

24. Hughes C, Murphy A, Martin C, Sheils O, O'Leary J: Molecular pathology of prostate cancer. J Clin Pathol 2005, 58:673-684.

25. Trojan L, Schaaf A, Steidler A, Haak M, Thalmann G, Knoll T, Gretz N, Alken P, Michel MS: Identification of metastasis-associated genes in prostate cancer by genetic profiling of human prostate cancer cell lines. Anticancer Res 2005, 25:183-191.

26. Prise KM, Schettino G, Folkard M, Held KD: New insights on cell death from radiation exposure. Lancet Oncol 2005, 6:520-528.

27. Gatti RA: The inherited basis of human radiosensitivity. Acta Oncol 2001, 40:702-711.

28. Serafin AM, Akudugu JM, Bohm L: Studies on the influence of DNA repair on radiosensitivity in prostate cell lines. Urol Res 2003, 31:227-231.
29. Roos WP, Binder A, Bohm L: Determination of the initial DNA damage and residual DNA damage remaining after 12 hours of repair in eleven cell lines at low doses of irradiation. Int J Radiat Biol 2000, 76:1493-1500.

30. Nunez MI, Villalobos M, Olea N, Valenzuela MT, Pedraza V, McMillan TJ, de Almodovar JMR: Radiation-induced DNA double-strand break rejoining in human tumour cells. Br J Cancer 1995, 71:311-316.

31. Papadaki C, Sfakianaki M, loannidis G, Lagoudaki E, Trypaki M, Tryfonidis K, Mavroudis D, Stathopoulos E, Georgoulias V, Souglakos J: ERCC1 and BRAC1 mRNA expression levels in the primary tumor could predict the effectiveness of the second-line cisplatin-based chemotherapy in pretreated patients with metastatic non-small cell lung cancer. J Thorac Oncol 2012, 7:663-671.

32. Casado JA, Rio P, Marco E, Garcia-Hernandez V, Domingo A, Perez L, Tercero JC, Vaquero JJ, Albella B, Gago F, Bueren JA: Relevance of the Fanconi anemia pathway in the response of human cells to trabectedin. Mol Cancer Ther 2008, 7:1309-1318.

33. Nogueira A, Catarino R, Faustino I, Nogueira-Silva C, Figueiredo T, Lombo L, Hilario-Silva I, Pereira D, Medeiros R: Role of the RAD51 G172T polymorphism in the clinical outcome of cervical cancer patients under concomitant chemoradiotherapy. Gene 2012, 504:279-283.

34. Yoshida K, Miki Y: Role of BRCA1 and BRCA2 as regulators of DNA repair, transcription, and cell cycle in response to DNA damage. Cancer Sci 2004, 95:866-871.

35. Hesling C, D'Incan M, D'Incan C, Souteyrand P, Monboisse J-C, Pasco S, Madelmont J-C, Bignon YJ: Downregulation of BRCA1 in A375 melanoma cell line increases radio-sensitivity and modifies metastatic and angiogenic gene expression. J Invest Dermatol 2004, 122:369-380.

36. Zhou C, Smith JL, Liu J: Role of BRCA1 in cellular resistance to paclitaxel and ionizing radiation in an ovarian cancer cell line carrying a defective BRCA1. Oncogene 2003, 22:2396-2404.

37. De Siervi A, De Luca P, Byun JS, Di LJ, Fufa T, Haggerty CM, Vazquez E, Moiola C, Longo DL, Gardner K: Transcriptional autoregulation by BRCA1. Cancer Res 2010, 70:532-542.

38. Wang A, Schneider-Broussard R, Kumar AP, MacLeod MC, Johnson DG: Regulation of BRCA1 expression by the Rb-E2F pathway. J Biol Chem 2000, 275:4532-4536.

39. Mallik I, Davila M, Tapia T, Schanen B, Chakrabarti R: Androgen regulates Cdc6 transcription through interactions between androgen receptor and E2F transcription factor in prostate cancer cells. Biochim Biophys Acta 2008, 1783:1737-1744

40. Hasselbach L, Haase S, Fischer D, Kolberg HC, Sturzbecher HW: Characterisation of the promoter region of the human DNA-repair gene Rad51. Eur J Gynaecol Oncol 2005, 26:589-598.

41. Horoszewicz JS, Leong SS, Kawinski E, Karr JP, Rosenthal H, Chu TM, Mirand EA, Murphy GP: LNCaP model of human prostatic carcinoma. Cancer Res 1983, 43:1809-1818.

42. Carroll AG, Voeller HJ, Sugars L, Gelmann EP: p53 oncogene mutations in three human prostate cancer cell lines. Prostate 1993, 23:123-134.

43. Kaighn ME, Narayan KS, Ohnuki Y, Lechner JF, Jones LW: Establishment and characterization of a human prostatic carcinoma cell line (PC-3). Investig Urol 1979, 17:16-23.

44. Prendergast NJ, Atkins MR, Schatte EC, Paulson DF, Walther PJ: p53 immunohistochemical and genetic alterations are associated at high incidence with post-irradiated locally persistent prostate carcinoma. J Urol 1996, 155:1685-1692.

45. Ritter MA, Gilchrist KW, Voytovich M, Chappell RJ, Verhoven BM: The role of p53 in radiation therapy outcomes for favorable-to-intermediate-risk prostate cancer. Int J Radiat Oncol Biol Phys 2002, 53:574-580.

46. Huang A, Gandour-Edwards R, Rosenthal SA, Siders DB, Deitch AD, White RW: $p 53$ and bcl-2 immunohistochemical alterations in prostate cancer treated with radiation therapy. Urology 1998, 51:346-351.

47. Stattin $\mathrm{P}$, Damber JE, Modig H, Bergh A: Pretreatment $\mathrm{p} 53$ immunoreactivity does not infer radioresistance in prostate cancer patients. Int J Radiat Oncol Biol Phys 1996, 35:885-889.

48. Keys HM, Bundy BN, Stehman FB, Muderspach LI, Chafe WE, Suggs CL 3rd, Walker JL, Gersell D: Cisplatin, radiation, and adjuvant hysterectomy compared with radiation and adjuvant hysterectomy for bulky stage IB cervical carcinoma. N Engl J Med 1999, 340:1154-1161.

49. Lo TC, Wiley AL Jr, Ansfield FJ, Brandenburg JH, Davis HL Jr, Gollin FF, Johnson RO, Ramirez G, Vermund H: Combined radiation therapy and 5-fluorouracil for advanced squamous cell carcinoma of the oral cavity 
and oropharynx: a randomized study. AJR Am J Roentgenol 1976, 126:229-235.

50. Vongtama V, Douglass HO, Moore RH, Holyoke ED, Webster JH: End results of radiation therapy, alone and combination with 5 -fluorouracil in colorectal cancers. Cancer 1975, 36:2020-2025.

51. Jassem J: Combined chemotherapy and radiation in locally advanced non-small-cell lung cancer. Lancet Oncol 2001, 2:335-342.

52. Clark JB, Ferris GM, Pinder S: Inhibition of nuclear NAD nucleosidase and poly ADP-ribose polymerase activity from rat liver by nicotinamide and 5'-methyl nicotinamide. Biochim Biophys Acta 1971, 238:82-85.

53. Wahlberg E, Karlberg T, Kouznetsova E, Markova N, Macchiarulo A, Thorsell A-G, Pol E, Frostell A, Ekblad T, Oncu D, Kull B, Robertson GM, Pellicciari R, Schuler H, Weigelt J: Family-wide chemical profiling and structural analysis of PARP and tankyrase inhibitors. Nat Biotechnol 2012, 30:283-288.

54. Tutt A, Robson M, Garber JE, Domchek SM, Audeh MW, Weitzel JN, Friedlander M, Arun B, Loman N, Schmutzler RK, Wardley A, Mitchell G, Earl $\mathrm{H}$, Wickens M, Carmichael J: Oral poly(ADP-ribose) polymerase inhibitor olaparib in patients with BRCA1 or BRCA2 mutations and advanced breast cancer: a proof-of-concept trial. Lancet 2010, 376:235-244.

55. Audeh MW, Carmichael J, Penson RT, Friedlander M, Powell B, Bell-McGuinn KM, Scott C, Weitzel JN, Oaknin A, Loman N, Lu K, Schmutzler RK, Matulonis $U$, Wickens M, Tutt A: Oral poly(ADP-ribose) polymerase inhibitor olaparib in patients with BRCA1 or BRCA2 mutations and recurrent ovarian cancer: a proof-of-concept trial. Lancet 2010, 376:245-251.

56. Fong PC, Yap TA, Boss DS, Carden CP, Mergui-Roelvink M, Gourley C, De Greve J, Lubinski J, Shanley S, Messiou C, A'Hern R, Tutt A, Ashworth A, Stone J, Carmichael J, Schellens JH, de Bono JS, Kaye SB: Poly(ADP)-ribose polymerase inhibition: frequent durable responses in BRCA carrier ovarian cancer correlating with platinum-free interval. J Clin Oncol 2010, 28:2512-2519.

57. Donawho CK, Luo Y, Luo Y, Penning TD, Bauch JL, Bouska JJ, Bontcheva-Diaz VD, Cox BF, DeWeese TL, Dillehay LE, Ferguson DC, Ghoreishi-Haack NS, Grimm DR, Guan R, Han EK, Holley-Shanks RR, Hristov B, Idler KB, Jarvis K, Johnson EF, Kleinberg LR, Klinghofer V, Lasko LM, Liu X, Marsh KC, McGonigal TP, Meulbroek JA, Olson AM, Palma JP, Rodriguez LE, et al: ABT-888, an orally active poly (ADP-ribose) polymerase inhibitor that potentiates DNA-damaging agents in preclinical tumor models. Clin Cancer Res 2007, 13:2728-2737.

58. Sauve $A A: N A D+$ and vitamin $B 3:$ from metabolism to therapies. J Pharmacol Exp Ther 2008, 324:883-893.

59. Choudhury A, Zhao H, Jalali F, Al Rashid S, Ran J, Supiot S, Kiltie AE, Bristow RG: Targeting homologous recombination using imatinib results in enhanced tumor cell chemosensitivity and radiosensitivity. Mol Cancer Ther 2009, 8:203-213.

60. Qiao B, Kerr M, Groselj B, Teo MTW, Knowles MA, Bristow RG, Phillips RM, Kiltie AE: Imatinib radiosensitizes bladder cancer by targeting homologous recombination. Cancer Res 2013, 73:1611-1620.

61. Russell JS, Brady K, Burgan WE, Cerra MA, Oswald KA, Camphausen K, Tofilon PJ: Gleevec-mediated inhibition of Rad51 expression and enhancement of tumor cell radiosensitivity. Cancer Res 2003, 63:7377-7383.

doi:10.1186/1471-2407-14-808

Cite this article as: Young et al:: RNA-seq profiling of a radiation resistant and radiation sensitive prostate cancer cell line highlights opposing regulation of DNA repair and targets for radiosensitization. BMC Cancer 2014 14:808.

\section{Submit your next manuscript to BioMed Central and take full advantage of:}

- Convenient online submission

- Thorough peer review

- No space constraints or color figure charges

- Immediate publication on acceptance

- Inclusion in PubMed, CAS, Scopus and Google Scholar

- Research which is freely available for redistribution 